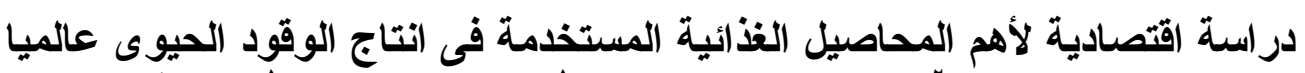

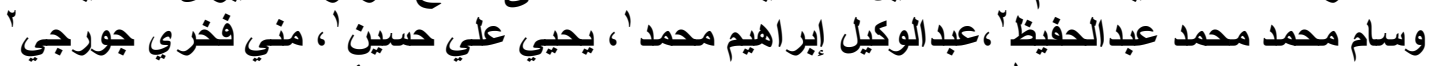

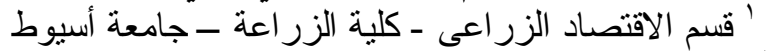

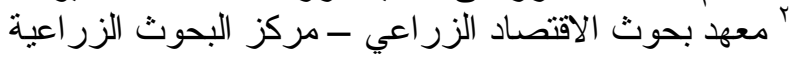

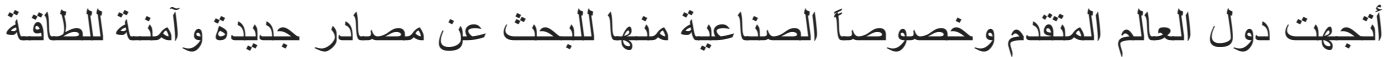

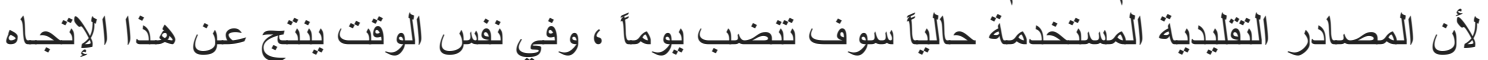

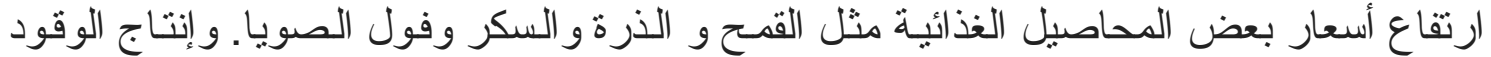

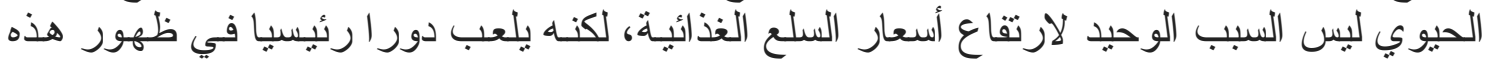

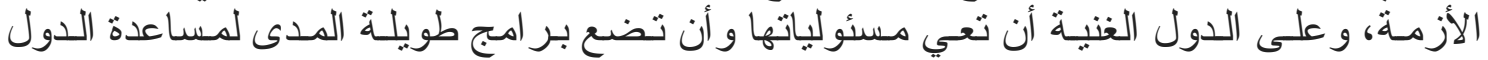

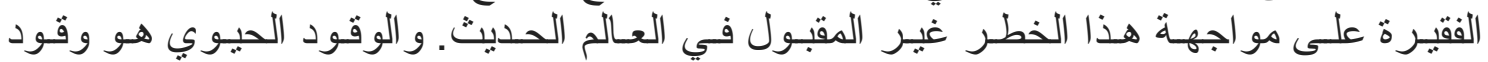

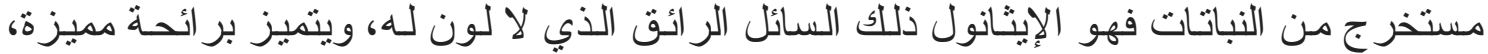

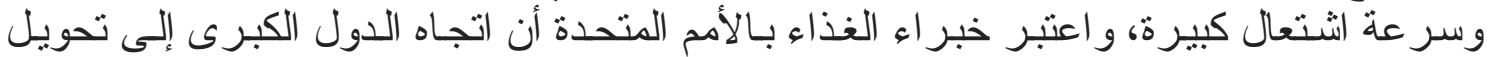

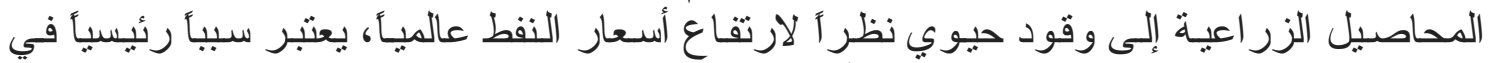

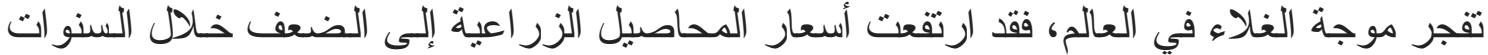

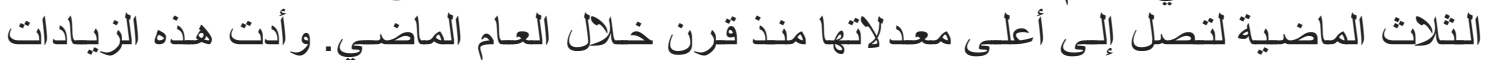

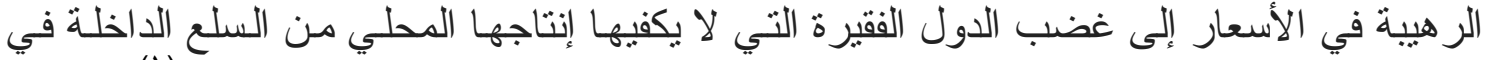

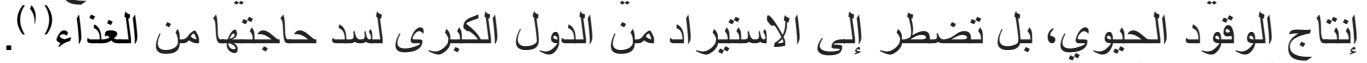
مثكلة الار اسة: تتمتل مشكلة هذا البحث في زيادة طلب الدول المتقدمة علي بعض الحاصلات الزر اعية

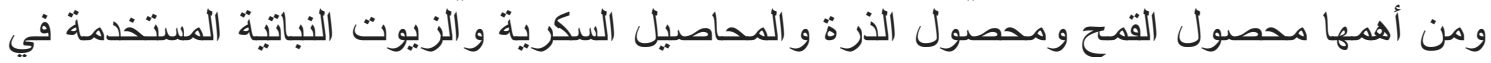

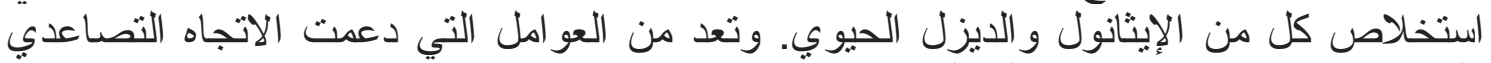

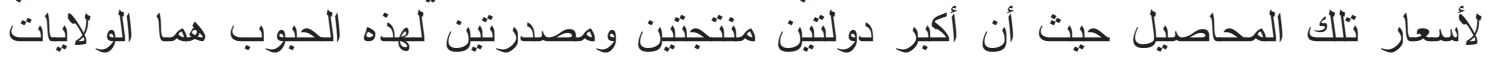

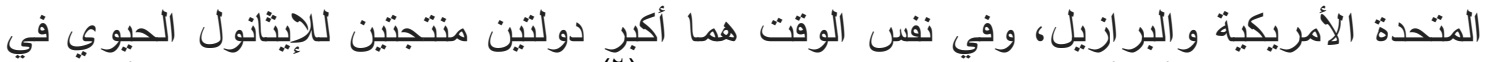

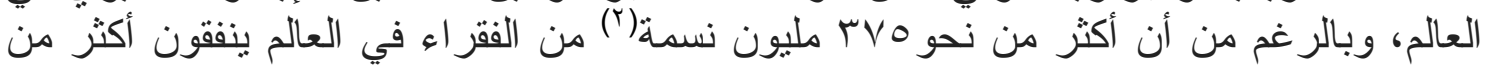

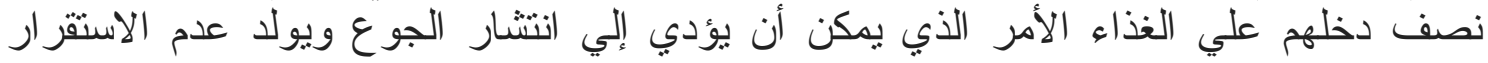

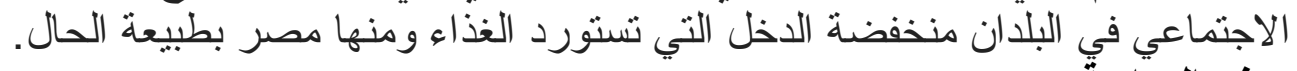

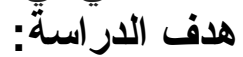

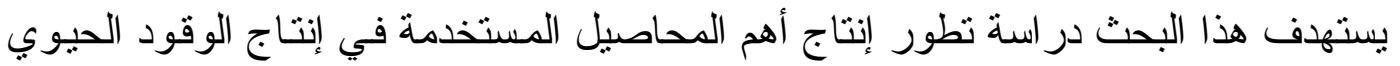

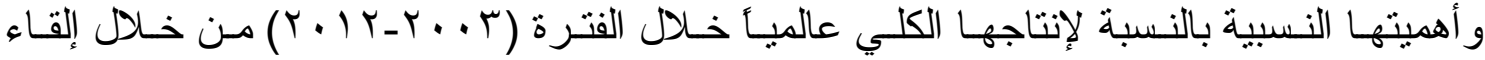

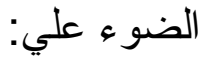

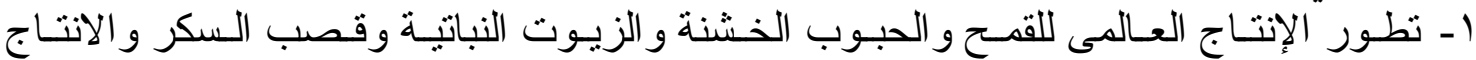

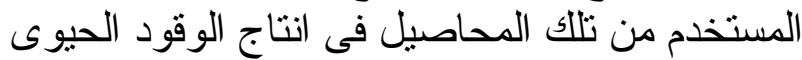

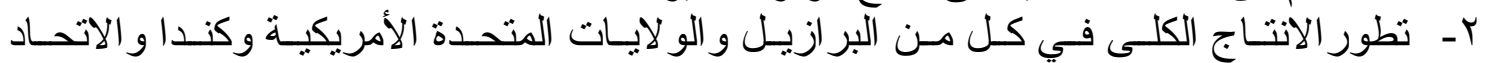

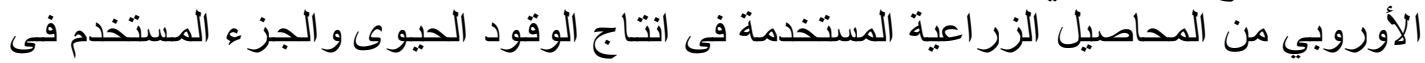

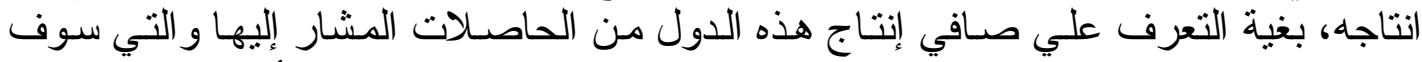

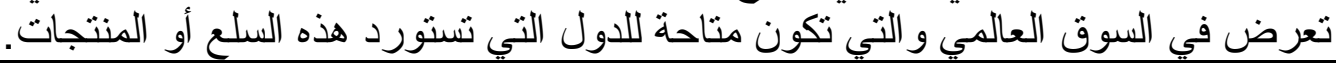

Received on: 5/2/2014

Referees: Prof. Mohamed A. Abo-Nahoul Accepted for publication on: 6/3/2014 Prof. Mohamed A. Mohamed 


$$
\text { مصادر البيانات و الأسلوب البحثي: }
$$

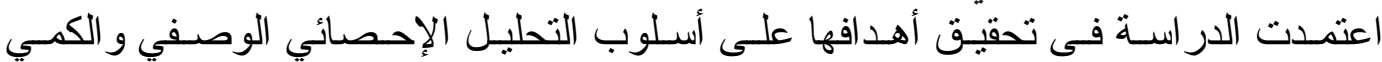

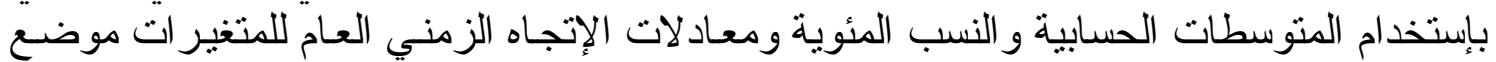

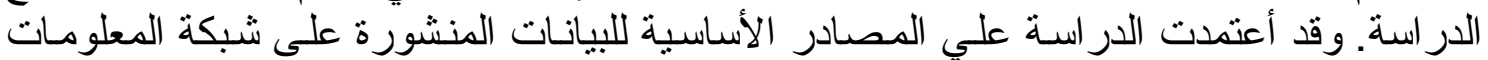

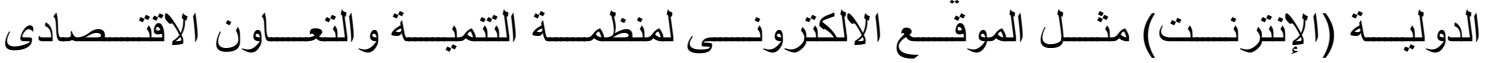

.WWw.oecd.org

النتائج البحثية:

أولا: تطور الإنتاج العالمي للمحاصيل المستخدمة فى انتاج الوقود الحيوى :

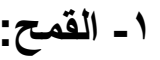

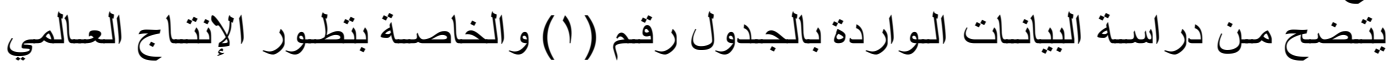

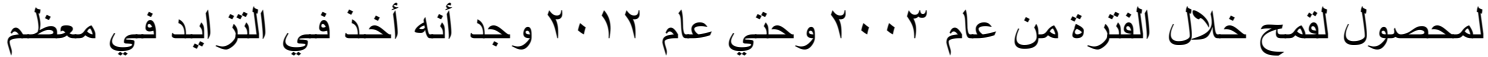

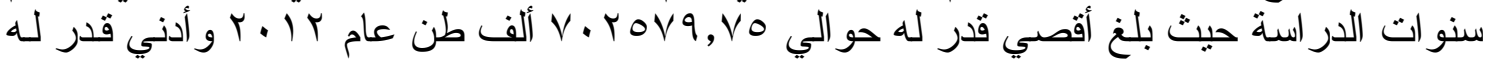

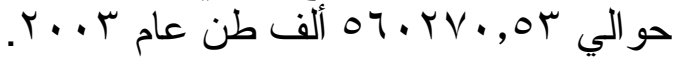

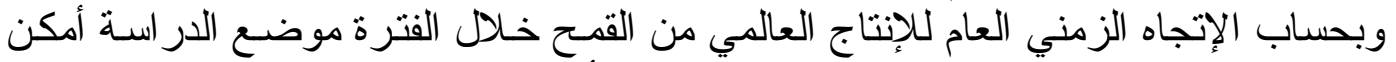

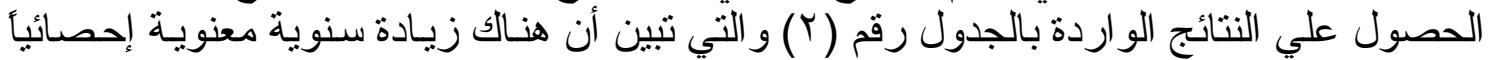

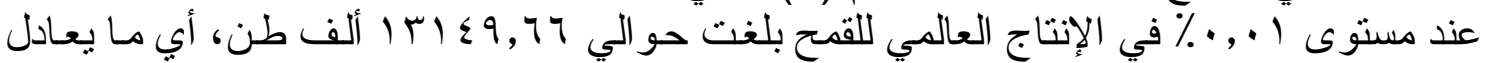

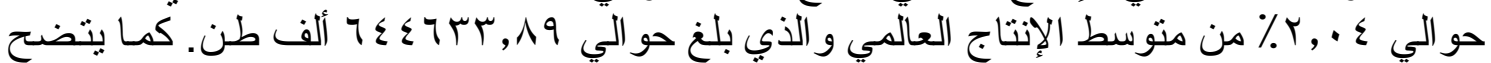

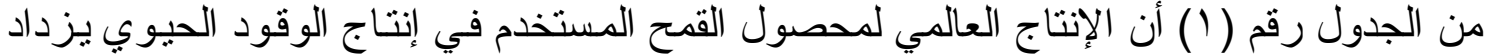

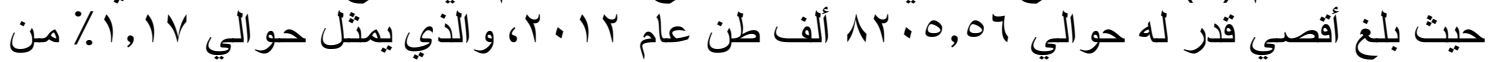

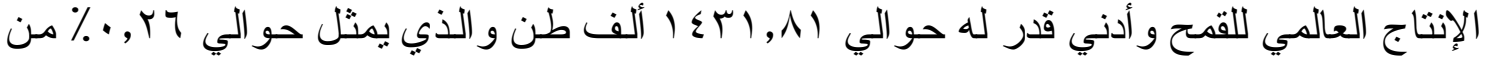

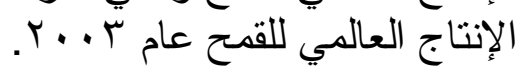

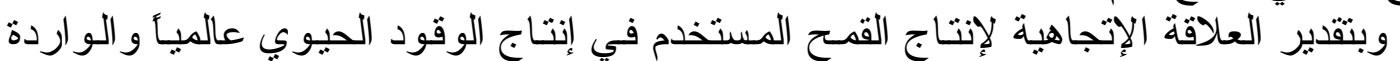

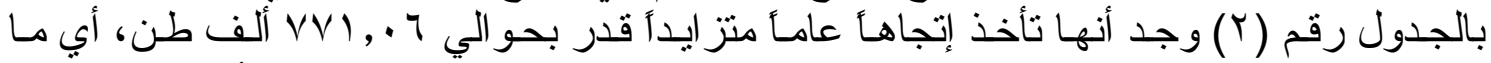

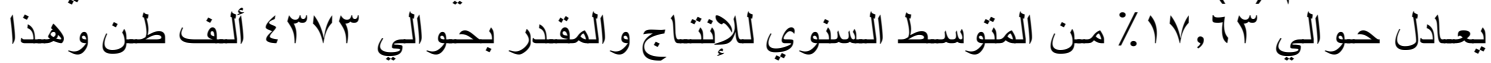

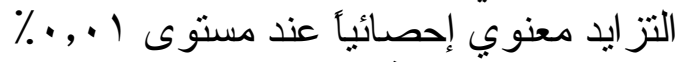

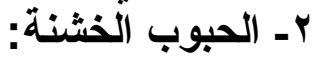

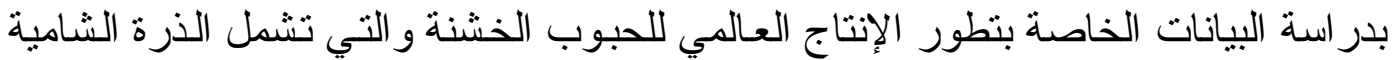

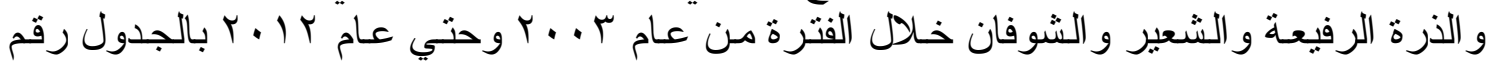

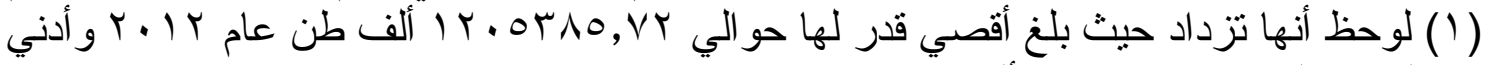

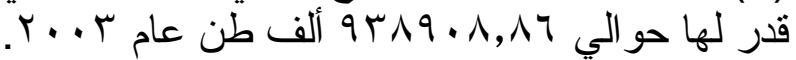

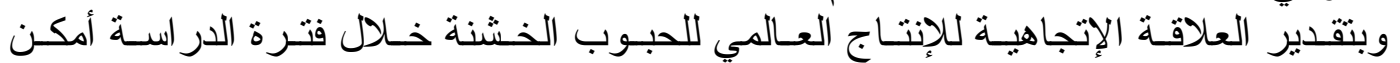

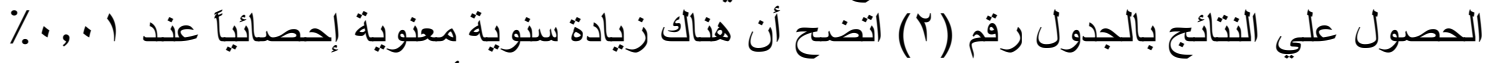

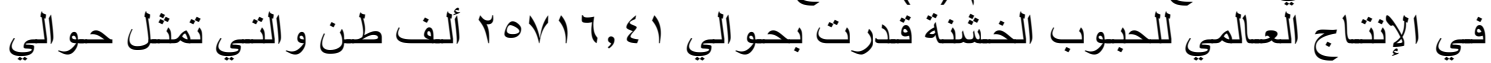

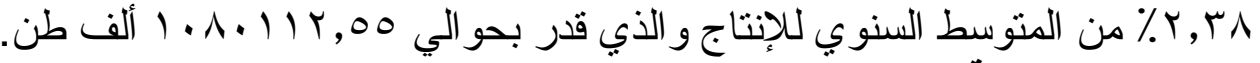

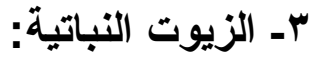

بدر اسة البيانات الموضحة بالجدول رقم ( ) (1) و الخاصة بتطور الإنتاج العالمي للزيوت خـلال

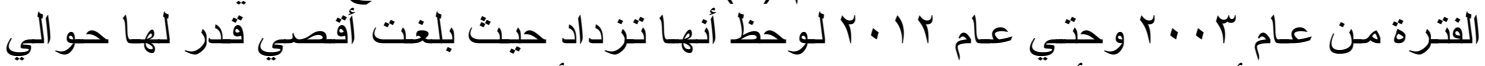
 
Assiut J. Agric. Sci., (45) No. (2) 2014 (163-180) (Special Issue)

(The $7^{\text {th }}$ Conference of Young Scientists) Fac. of Agric. Assiut University April, 28, 2014. 
محمد واخرين ع 1 r 


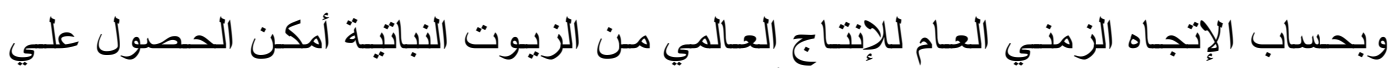

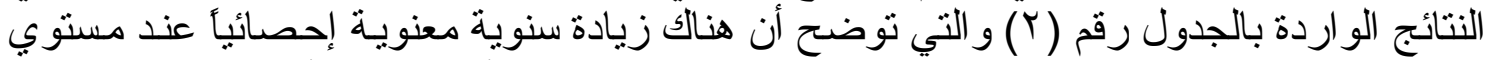

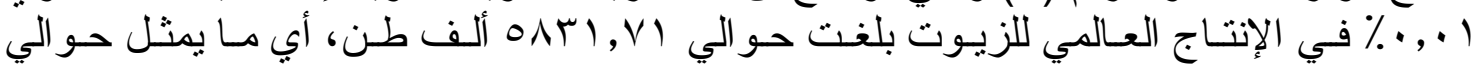

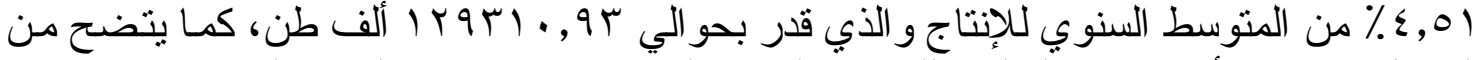

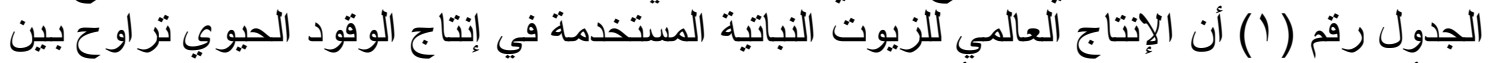

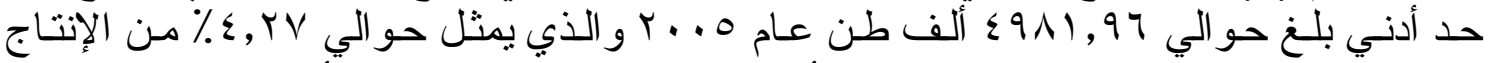

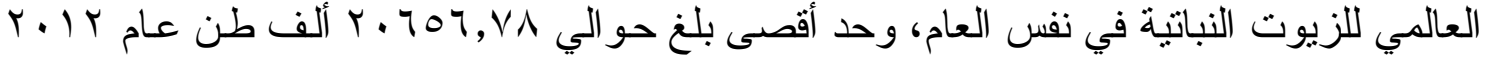

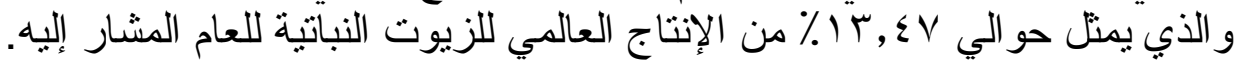

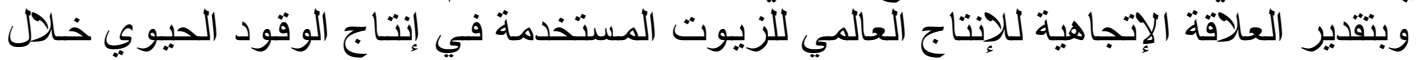

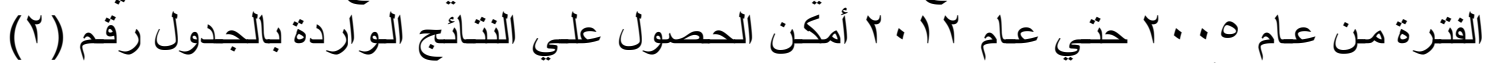

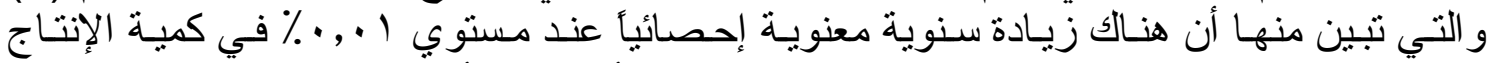

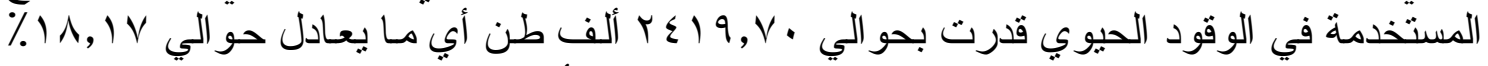

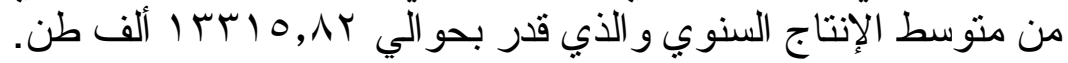

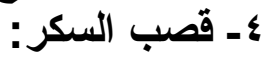

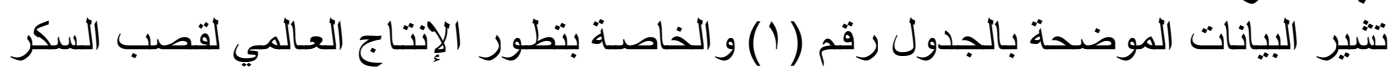

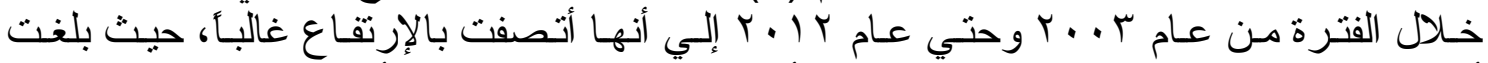

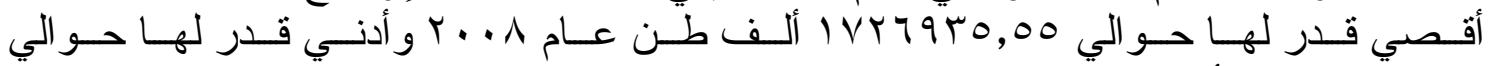

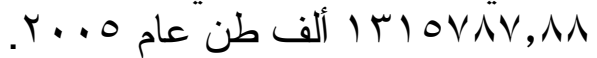

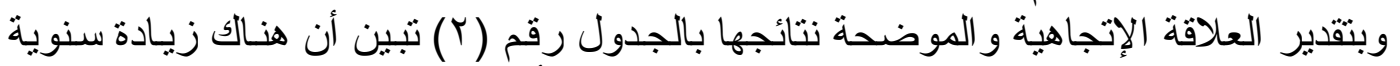

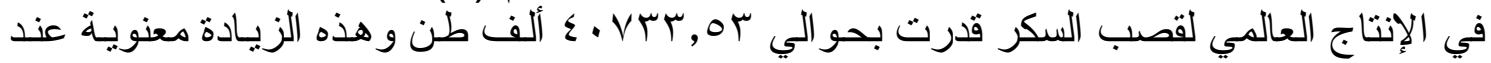

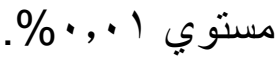
كما تثير بيانات الجدول رقم ( (1) إلي أن الإنتاج العالمي لقصب السكر المستخدم في إنتاج

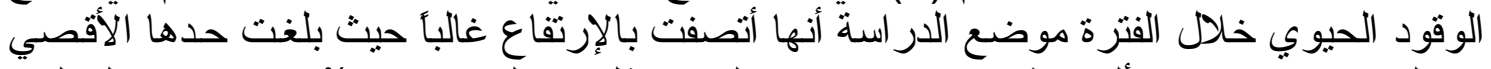

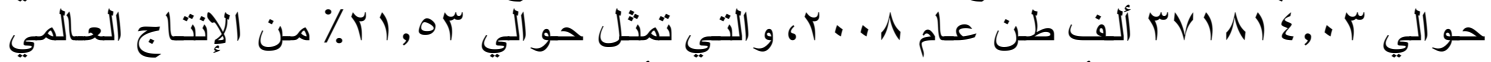

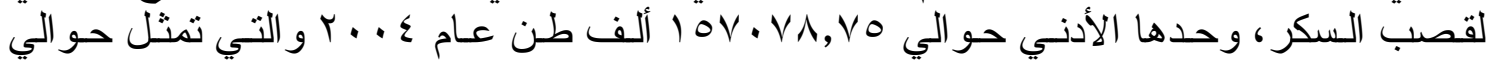
1), VV

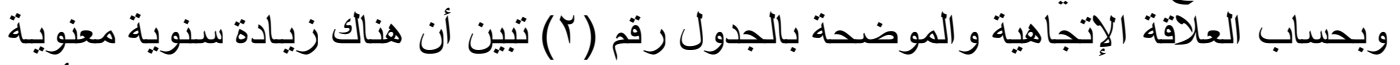

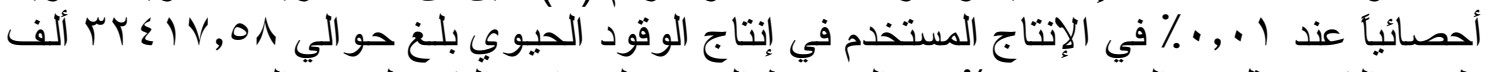

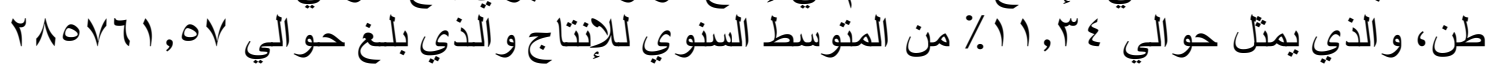

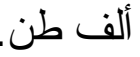

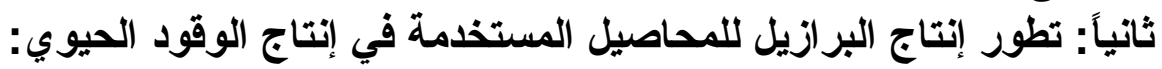

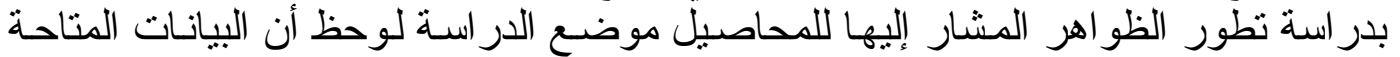

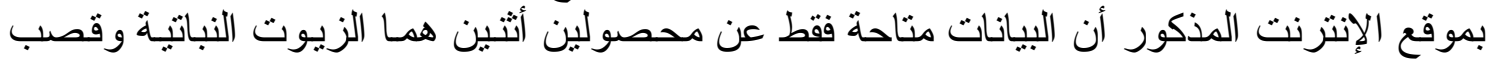

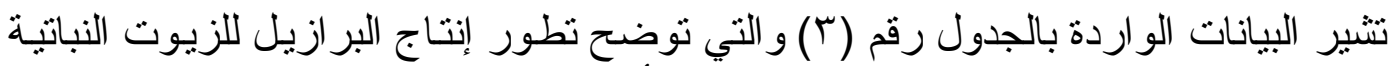

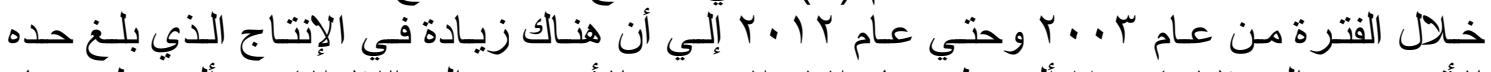

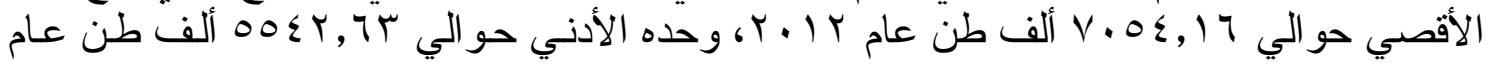

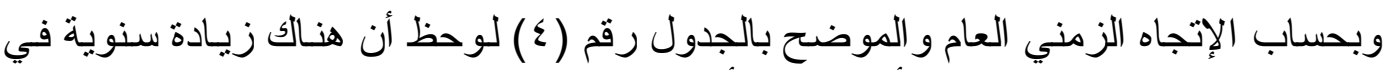

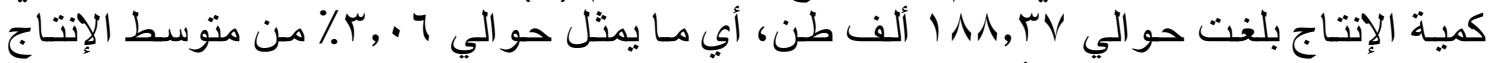

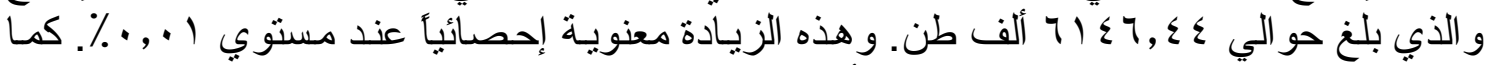

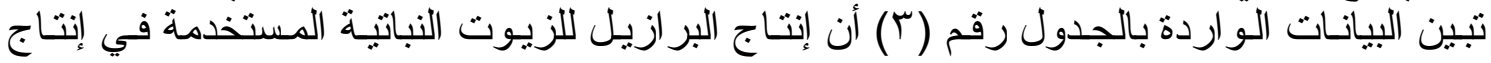

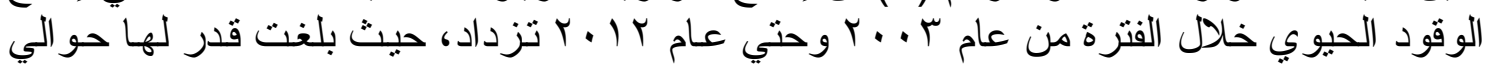




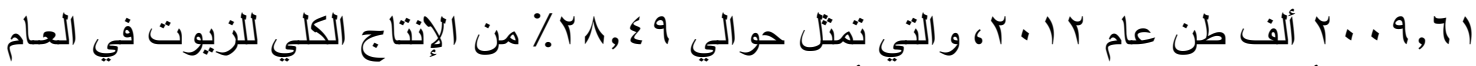

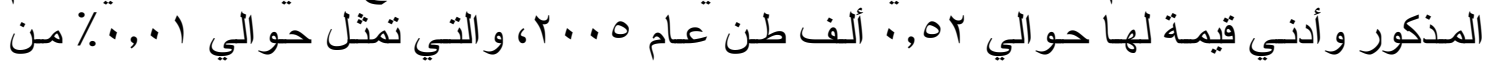

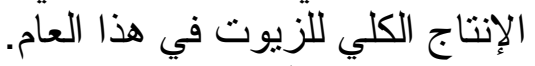

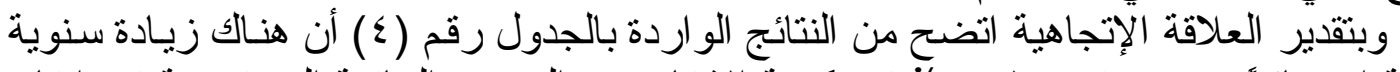

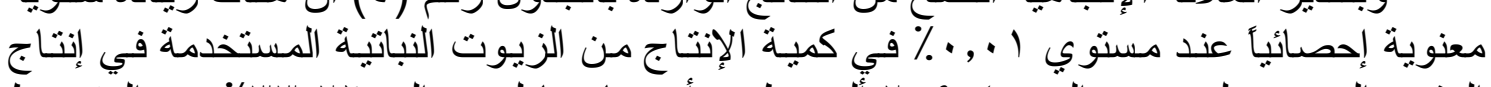

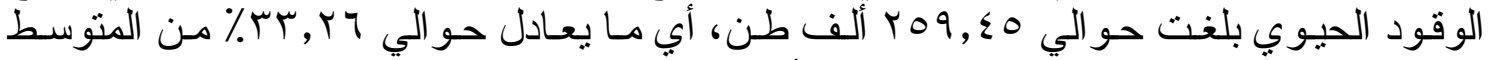

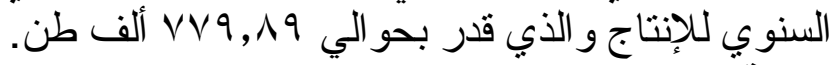

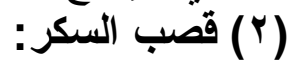

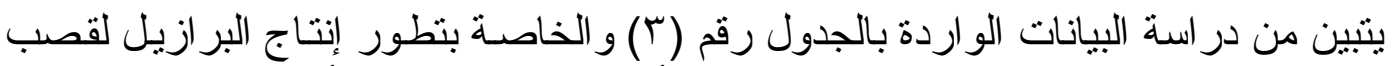

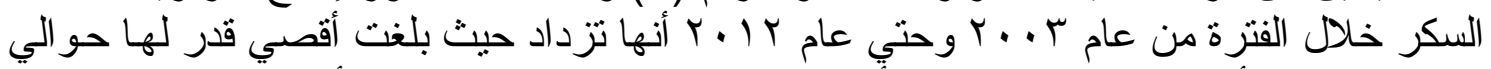

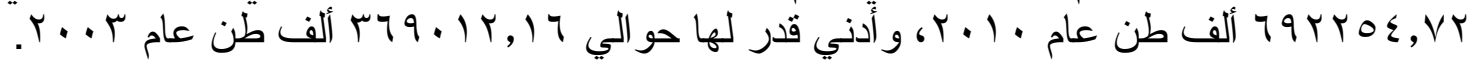

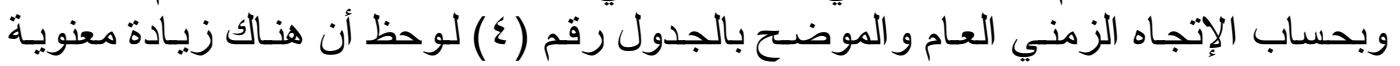

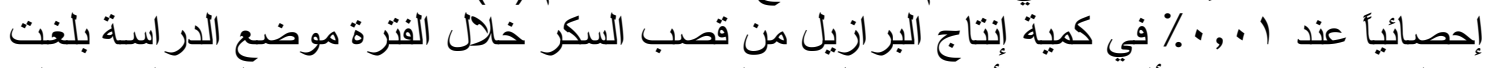

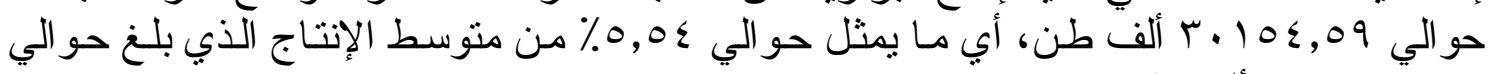
أخ

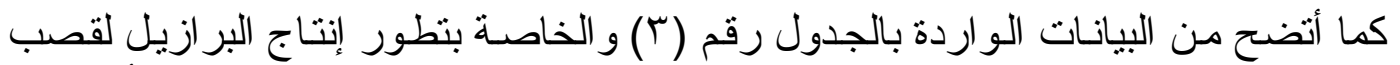

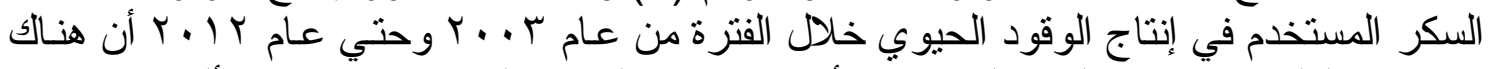

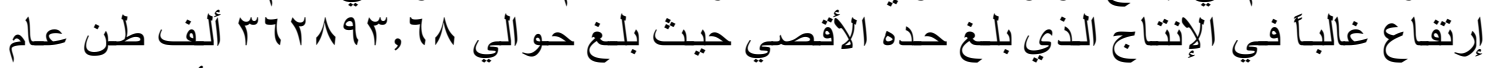

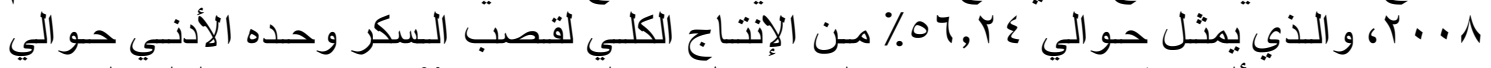

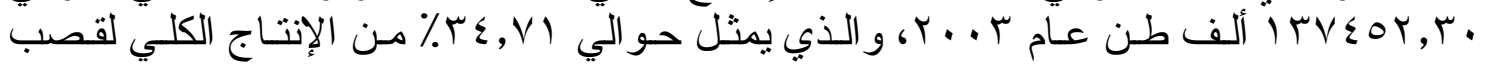

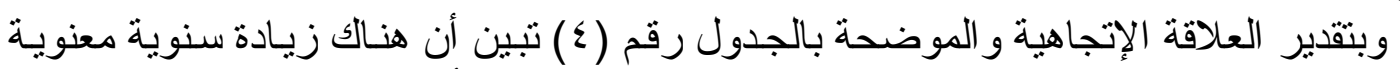

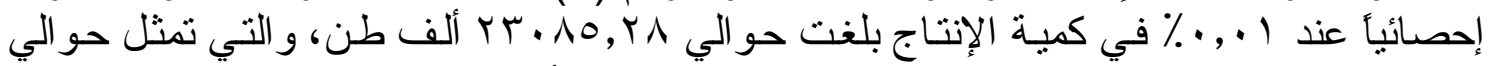

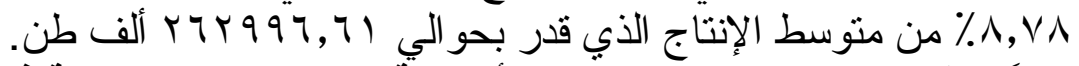

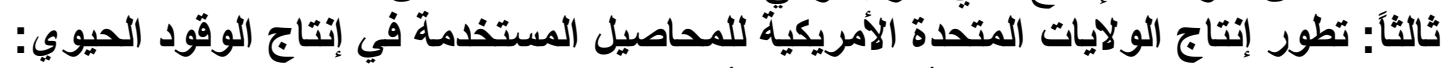

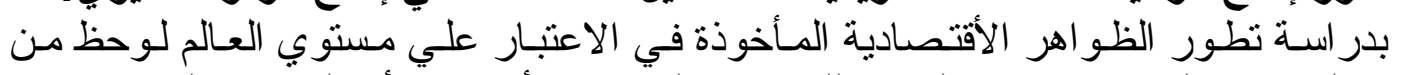

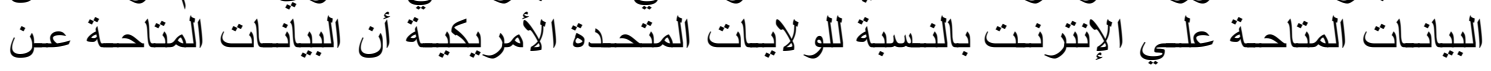

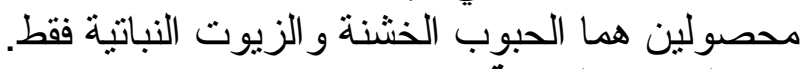

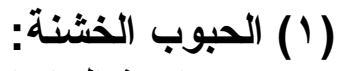

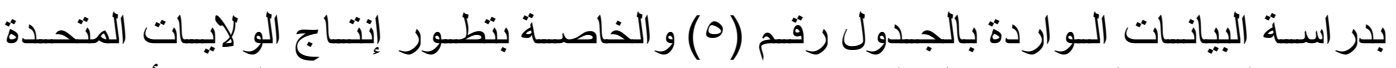

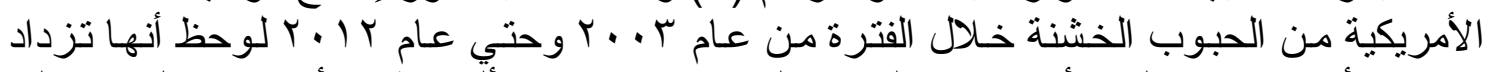

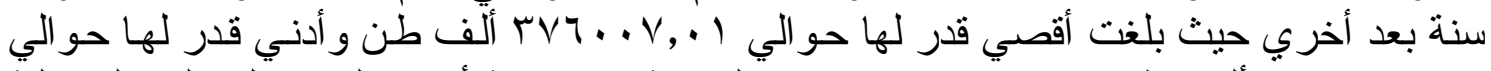

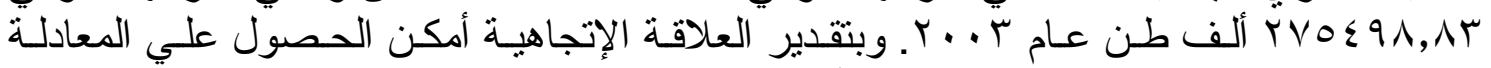

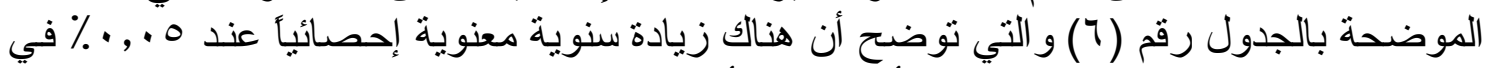

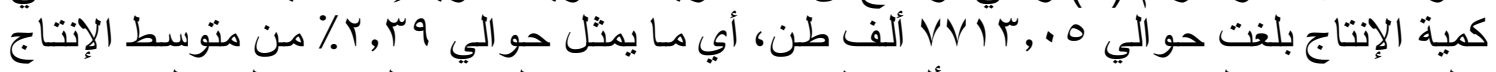

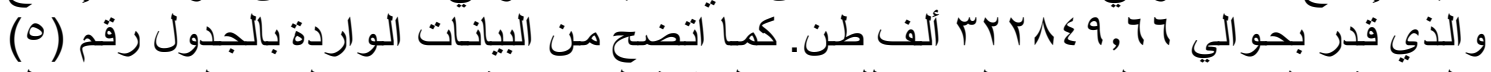

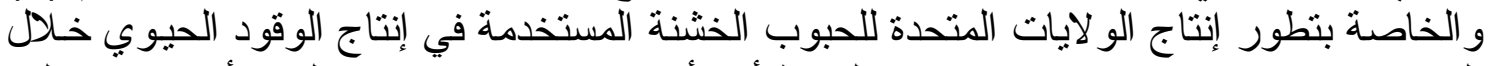

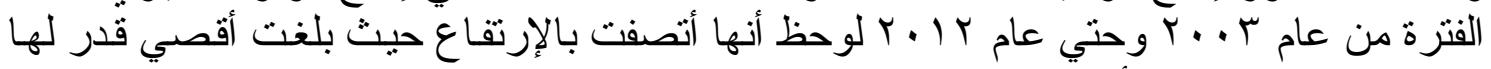

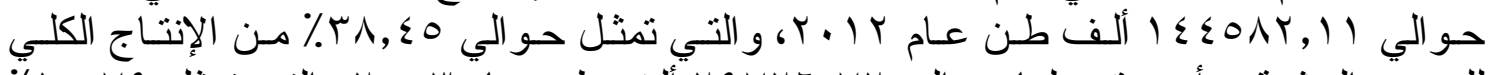

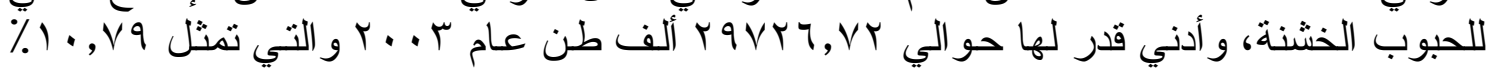

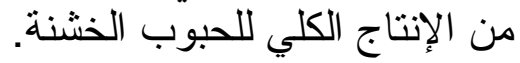


Assiut J. Agric. Sci., (45) No. (2) 2014 (163-180) (Special Issue)

(The $7^{\text {th }}$ Conference of Young Scientists) Fac. of Agric. Assiut University April, 28, 2014. 
محمد واخرين ع 1 r 


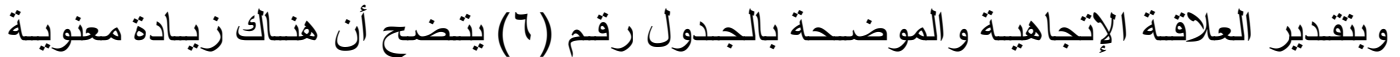

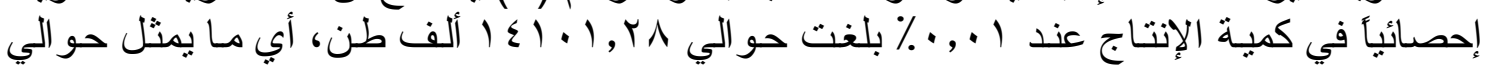

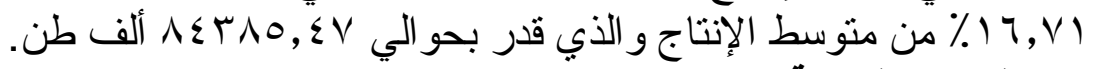
( الزيوت النباتية (r)

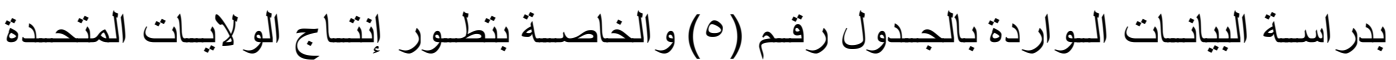

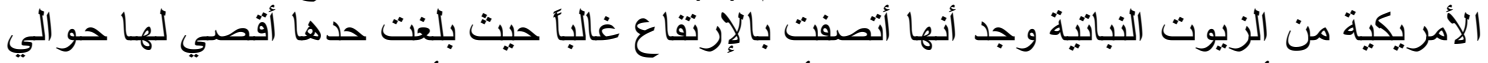

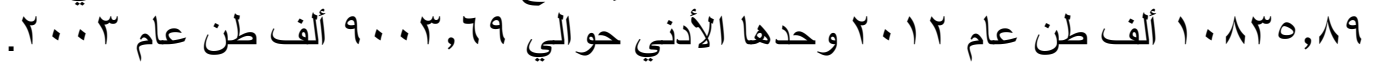

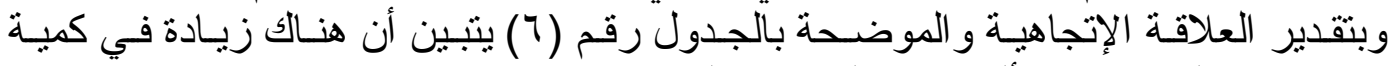

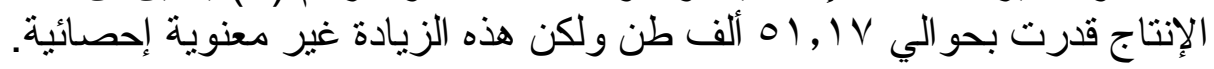

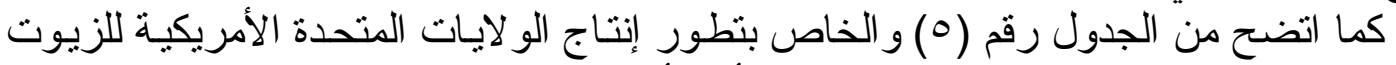

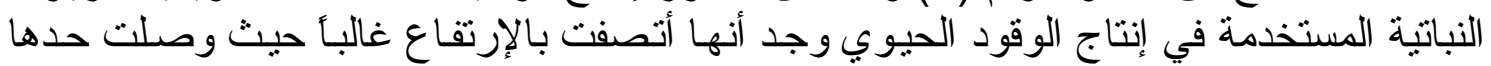

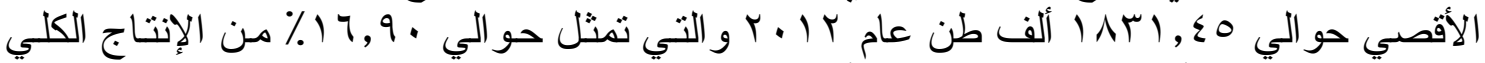

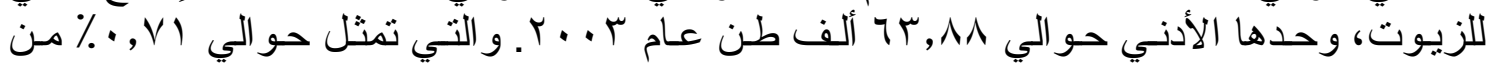

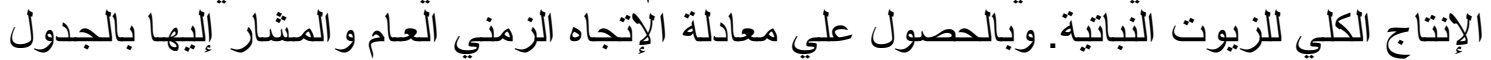

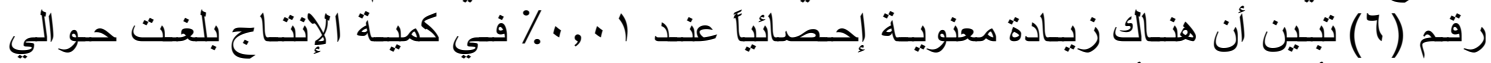

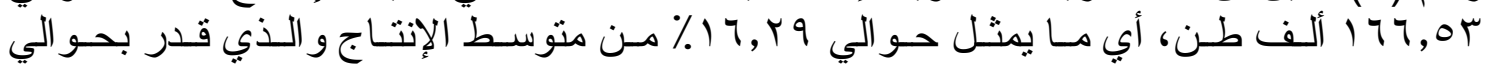

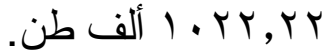
رابعاً: تطور إنتاج كندا للمحاصيل المستخدمة في إنتاج الوقود الحيوي:

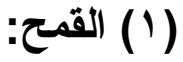

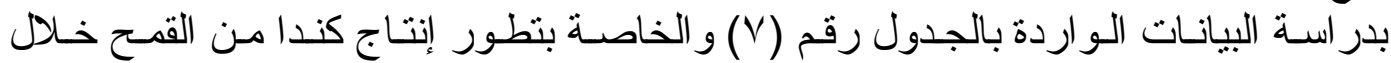

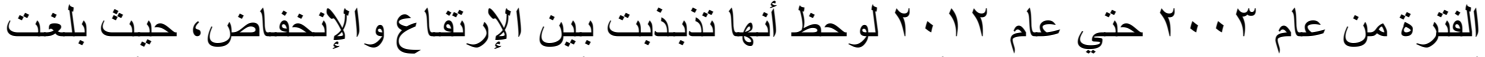

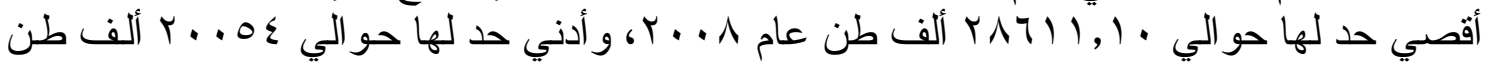
عام V... وبحساب الإتجاه الزمني العام و الموضتح بالجدول رقم (^) لوحظ أن هنالك زيادة سنوية في كمية الإنتاج ولكن هذه الزيادة غير معنوية إحصائياً.

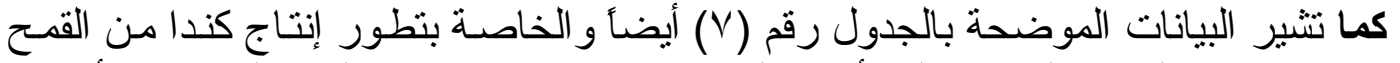

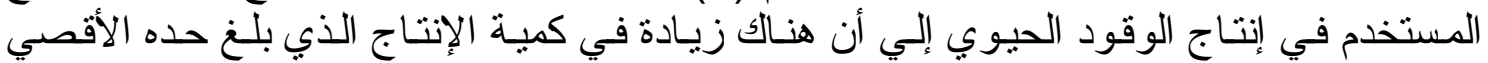

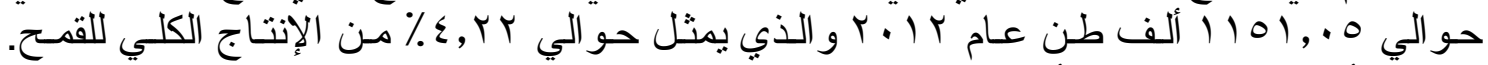

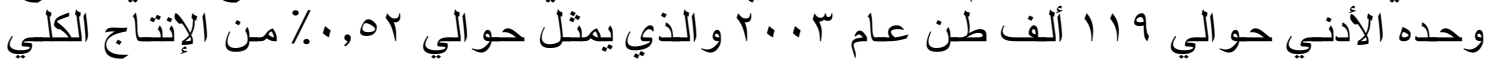
للقمح.

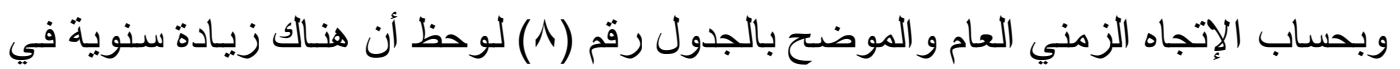

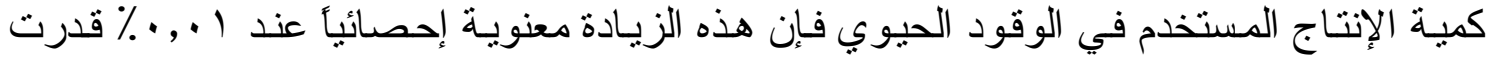

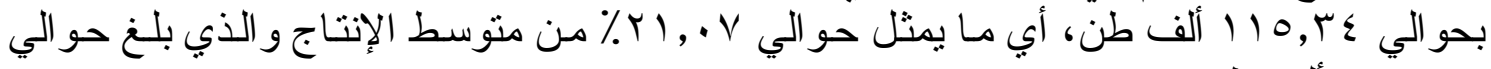

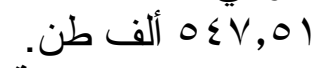

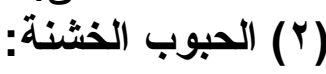

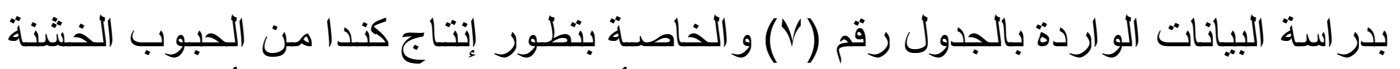

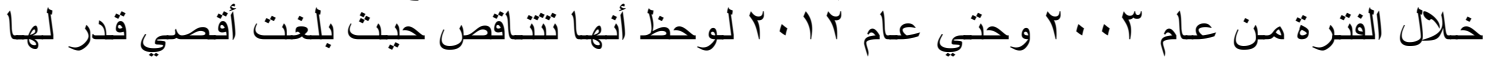
حو الي . وبتقدير العلاقـة الإتجاهيـة و الموضـحة بالجدول رقم (^) يتبين أن هنـاك تتـاقص في كميـة الإنتاج ولكن هذا التتاقص غير معنوي إحصائياً.

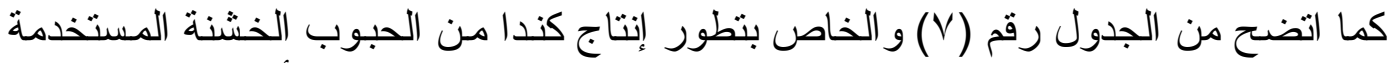

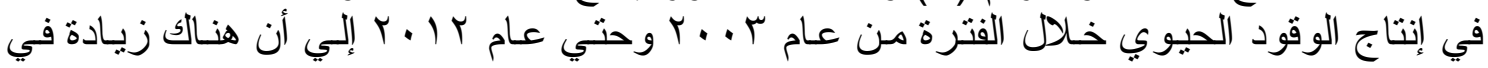




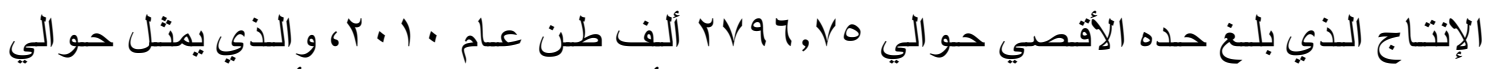

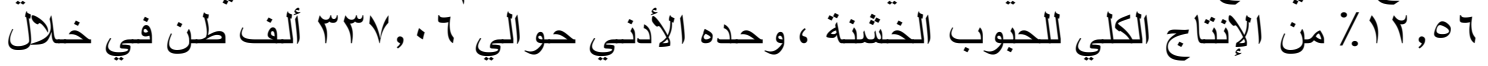

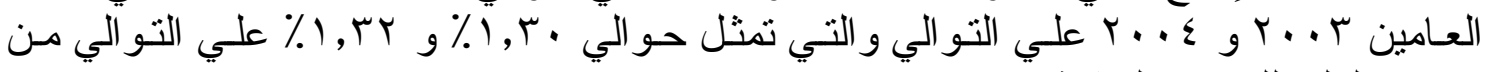
الإنتاج الكلي للحبوب الخشنة

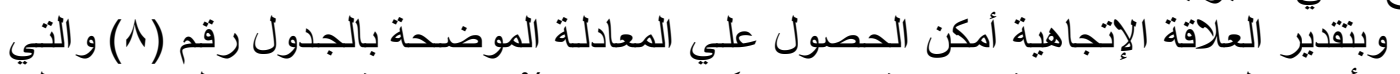

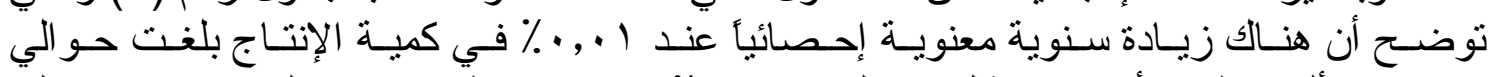

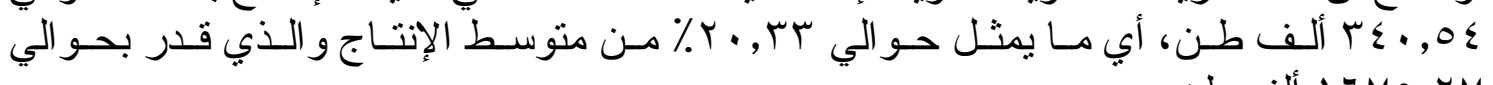
إن

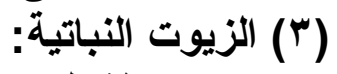

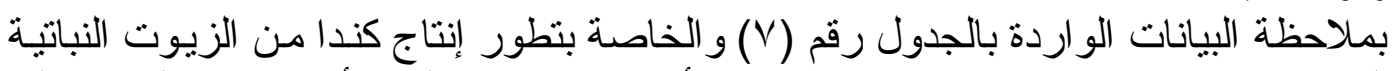

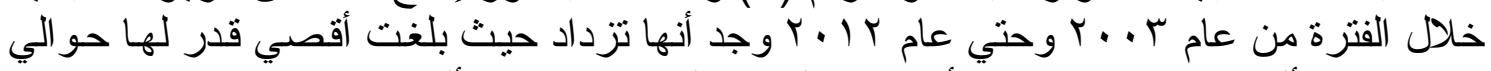

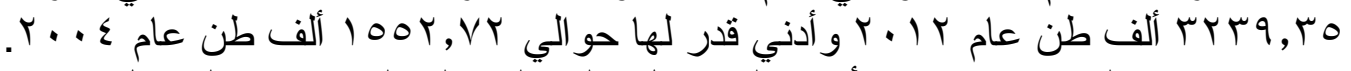

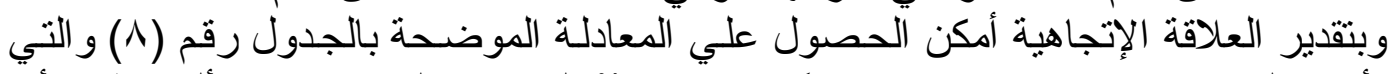

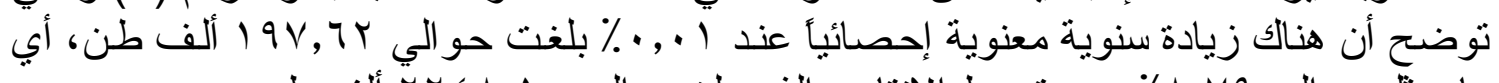

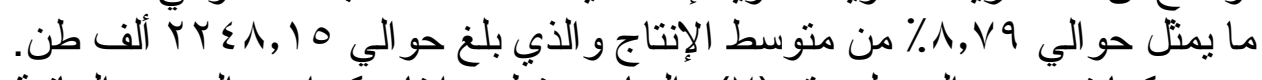

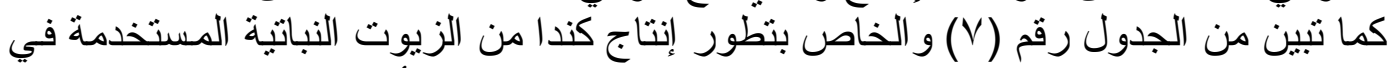

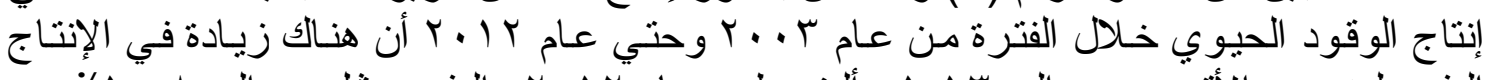

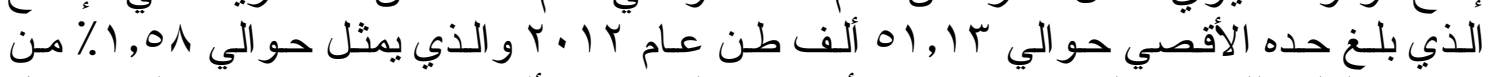

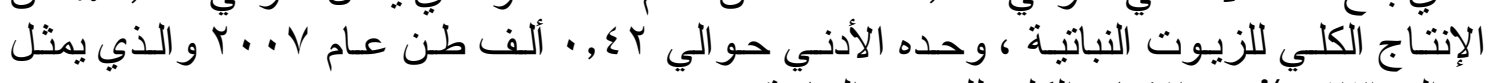

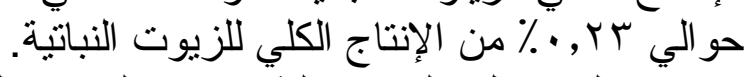

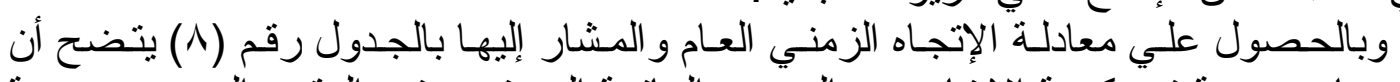

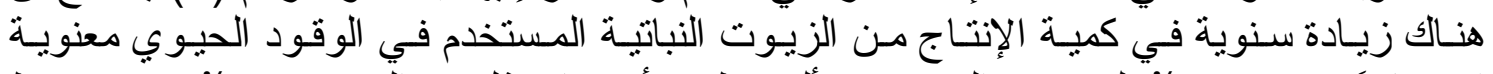

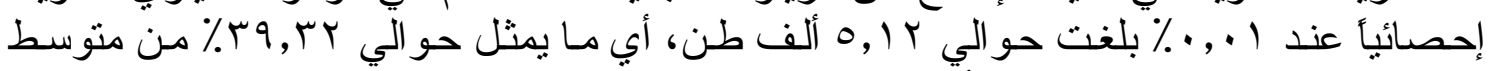

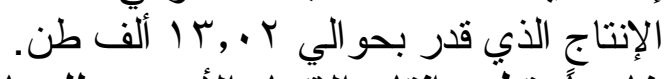
خامسأ: تطور إنتاج الإتحاد الأوروبي للمحاصيل المستخدمة في إنتاج الوقود الحيوي:

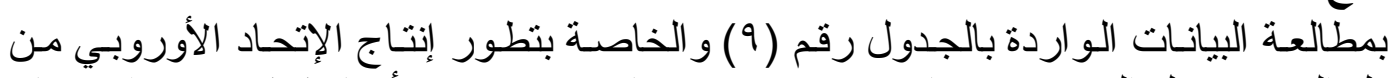

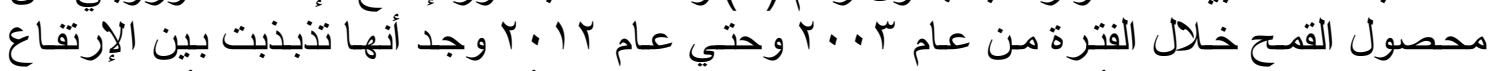

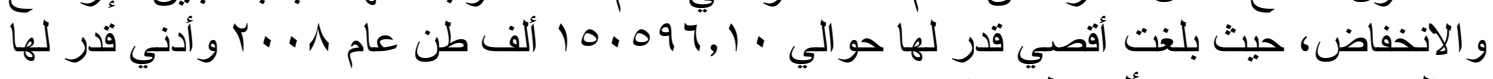

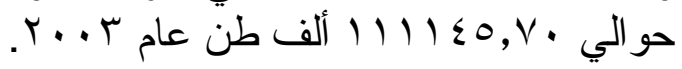
وبالحصول علي معادلة الإتجاه الزمني العام و المشار إليها في الجدول رقم ( • ( ) يتبين أن

هذه الزيادة غير معنوية إحصائيًا.

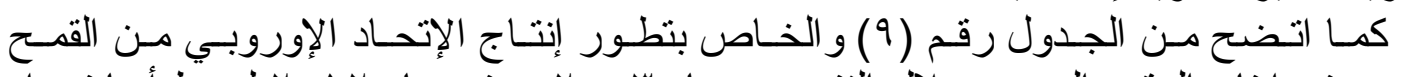

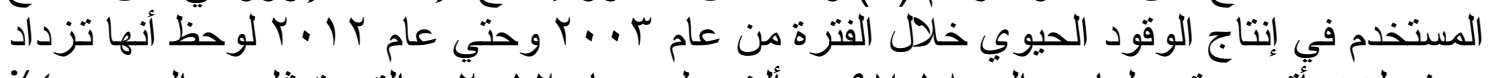

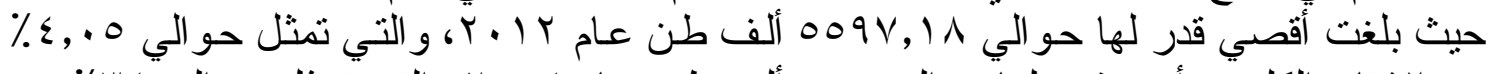

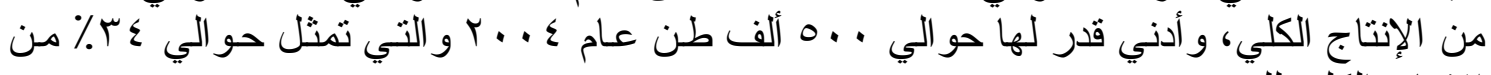
الإنتاج الكلي للقمح. 
Assiut J. Agric. Sci., (45) No. (2) 2014 (163-180) (Special Issue)

(The $7^{\text {th }}$ Conference of Young Scientists) Fac. of Agric. Assiut University April, 28, 2014. 
محمد واخرين \& 1 r r 
Assiut J. Agric. Sci., (45) No. (2) 2014 (163-180) (Special Issue)

(The $7^{\text {th }}$ Conference of Young Scientists) Fac. of Agric. Assiut University April, 28, 2014. 
محمد واخرين \& 1 r r 


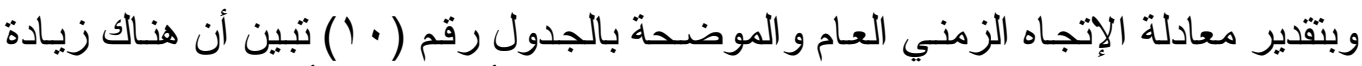

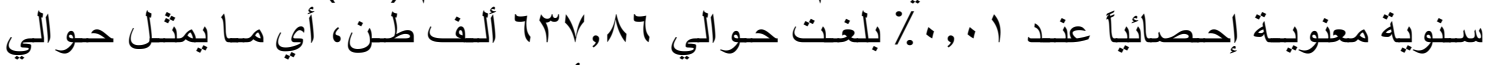

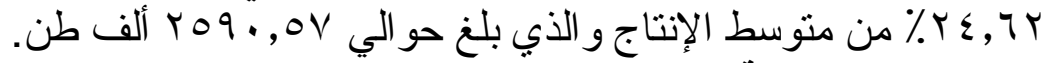

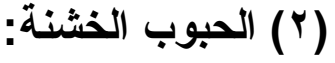

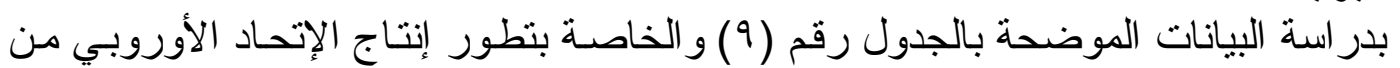

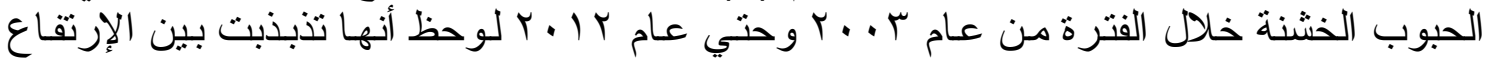

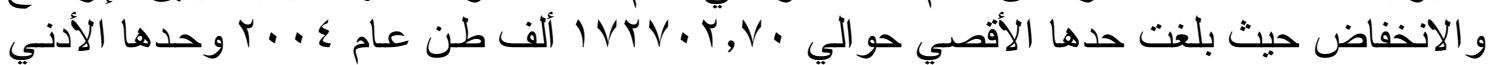

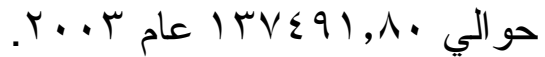

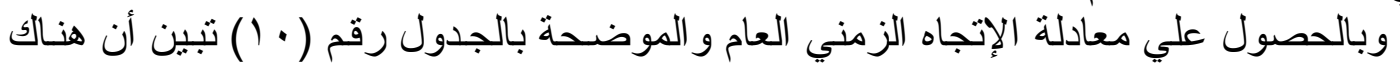

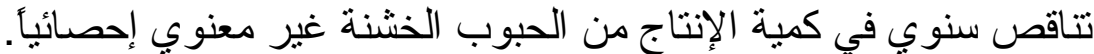

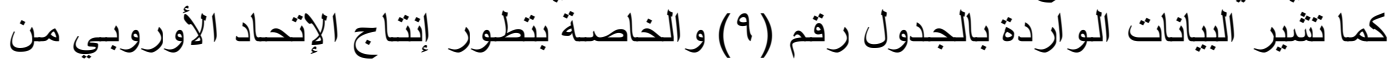

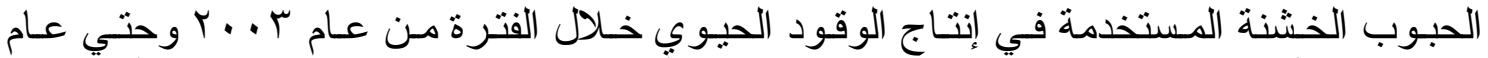

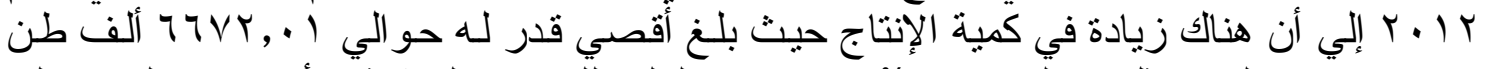

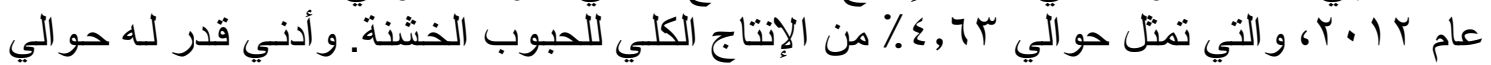

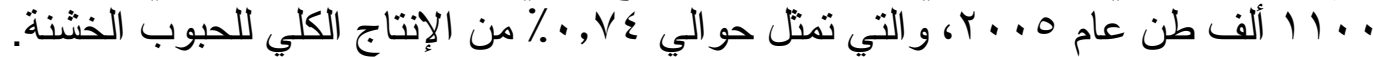

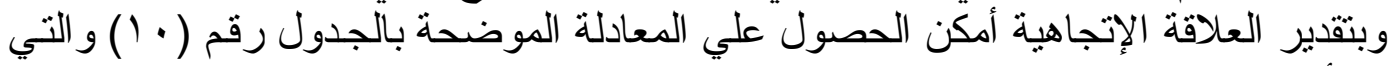

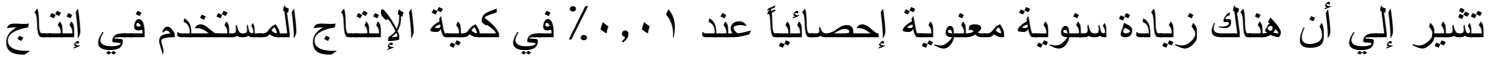

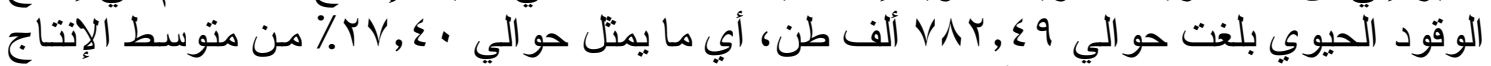

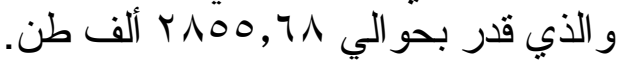

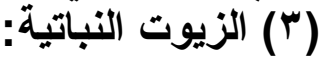

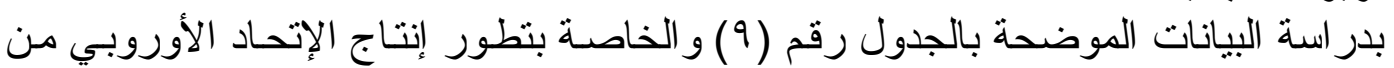

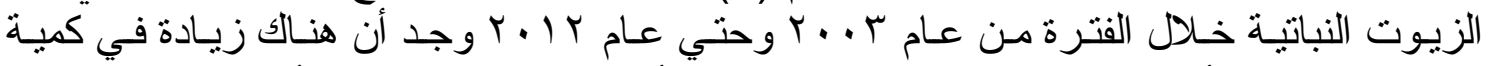

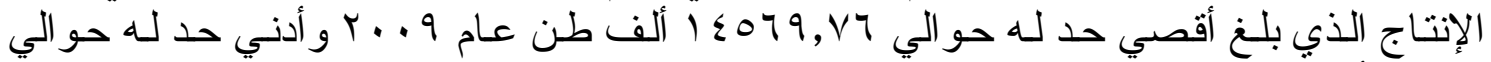

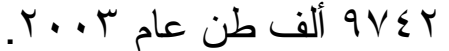

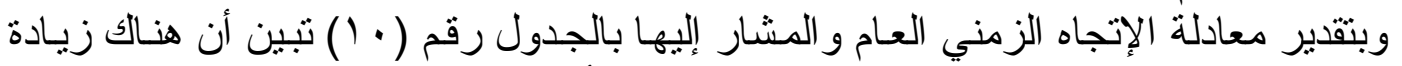

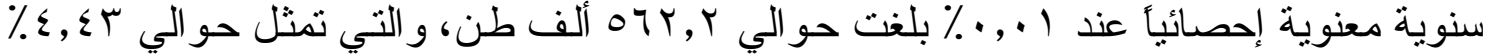

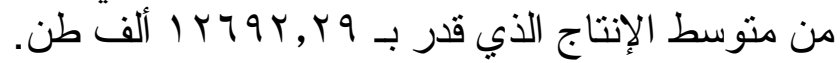

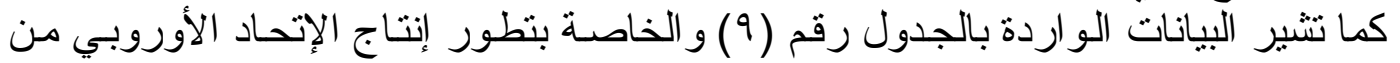

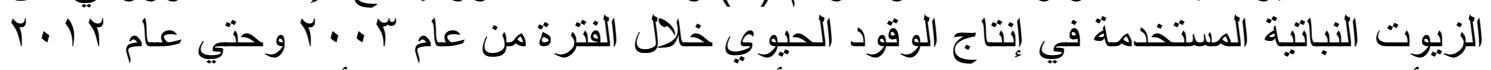

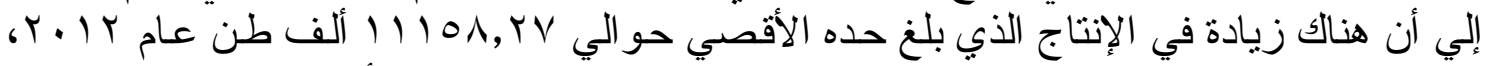

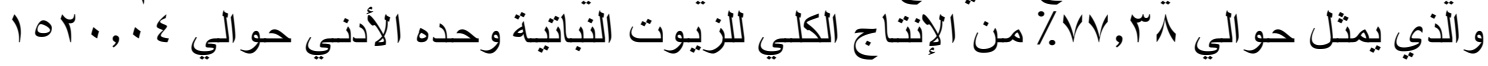

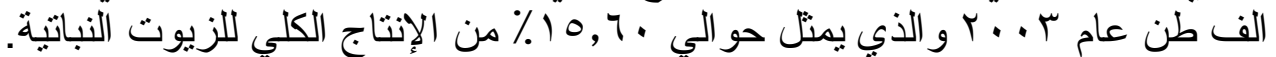

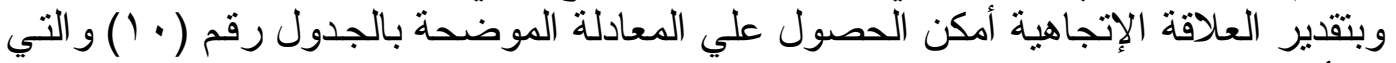

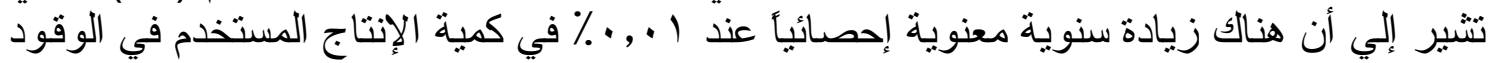

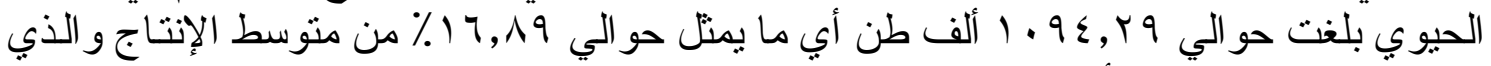

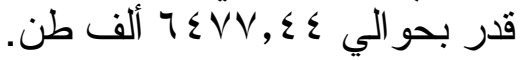

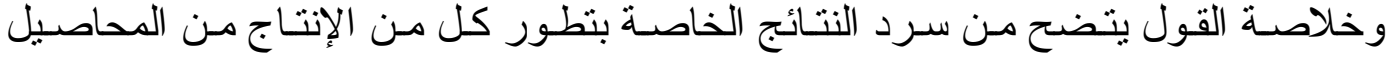

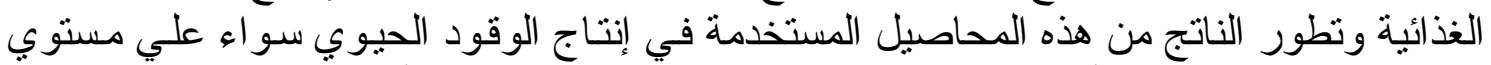

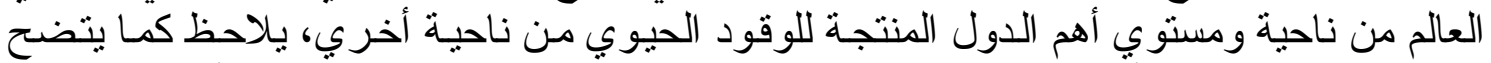

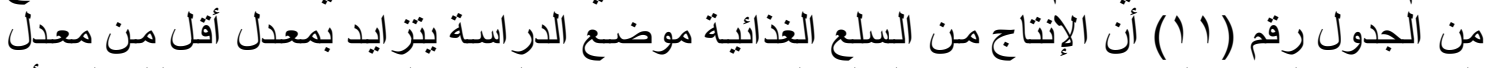

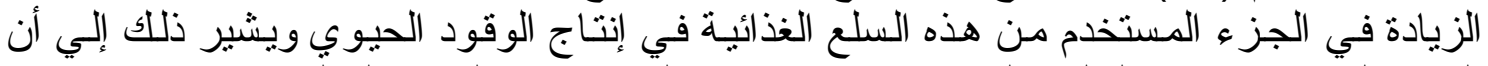

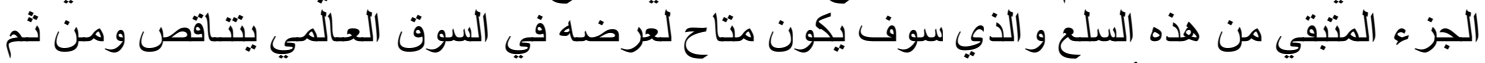
يؤدي ذلك إلي زيادة الأسعار العالمية لهذه المنتجات و علي ذلك سوف سوف يكون علي الدول 


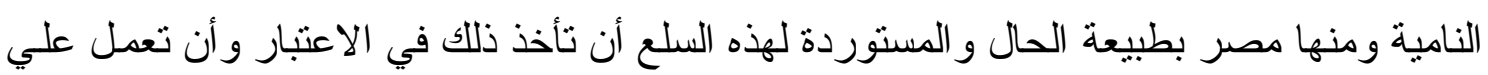
زيادة الإكتفاء الذاتي من هذه المنتجات حتي لا يؤثز ذلك إلي زيـادة العبء المتمثن في الو اردات

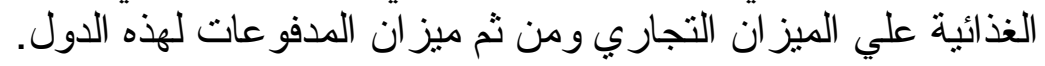

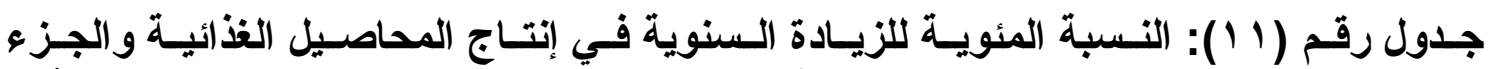

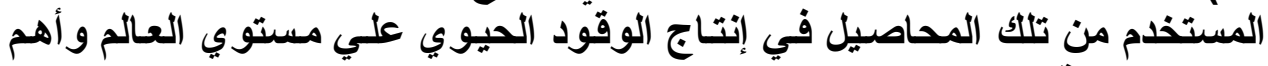

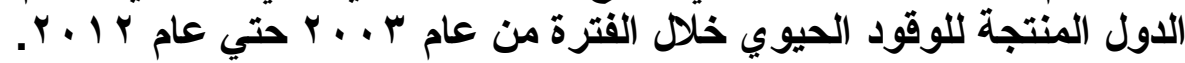

\begin{tabular}{|c|c|c|c|}
\hline 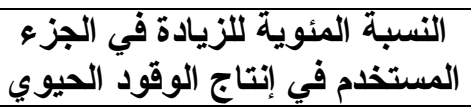 & النسبة المئوية للزيادة & السلعة & 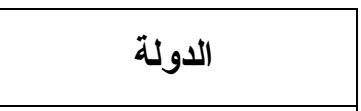 \\
\hline IV,Tr & $r, \cdot \varepsilon$ & قمح & 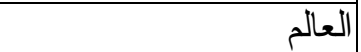 \\
\hline- & $r, \Gamma \wedge$ & حبوب خشنة & \\
\hline $1 \wedge, 1 V$ & $\varepsilon, 01$ & الزيوت النباتية & \\
\hline $11, r \varepsilon$ & T,TT & قصب السكر & \\
\hline ru, rt & $r, .7$ & الزيوت النباتية & البر ازيل \\
\hline$\wedge, \vee \wedge$ & $0,0 \leqslant$ & قصب السكر & \\
\hline $17, V 1$ & r,rq & الحبوب الخشنة & الو لايات المتحدة الأمريكية \\
\hline $17, Y 9$ & $\cdot, 0$ & الزيوت النباتية & \\
\hline YI, $\cdot V$ & $1, \cdot 1$ & القمح & كندا \\
\hline$r \cdot, r$ & $1, \leqslant 1$ & الحبوب الخشنة & \\
\hline rq,rr & $\wedge, \vee q$ & الزيوت النباتية & \\
\hline Y\&,TY & $\cdot, 99$ & القمح & الإتحاد الأوروبي \\
\hline TV,乏. & $\cdot, \mu_{0}$ & الحبوب الخشنة & \\
\hline $17, \wedge 9$ & $\varepsilon, \varepsilon \Gamma$ & الزيوت النباتية & \\
\hline
\end{tabular}

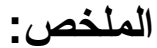

الوقود الحيوي هو وقود مستخر ج مـن بعض الحاصـلات الحقليـة و الإيثنانول ذلك السائل

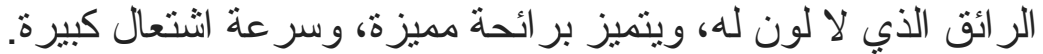

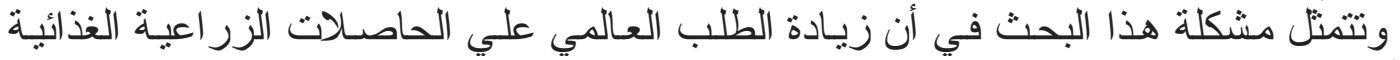

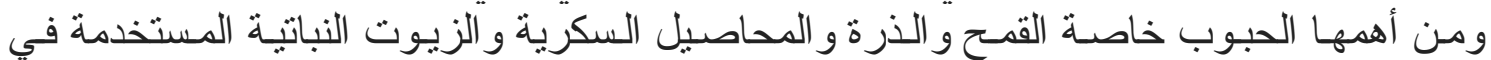

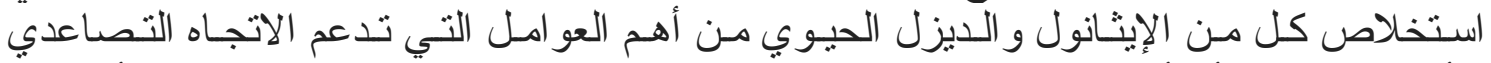

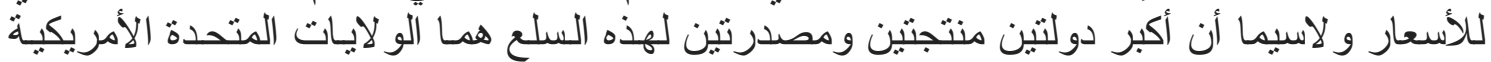

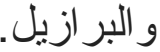

وقد استهدف البحث در اسة تطور إنتاج أهم المحاصيل المستخدمة في إنتاج الوقود الحيوي

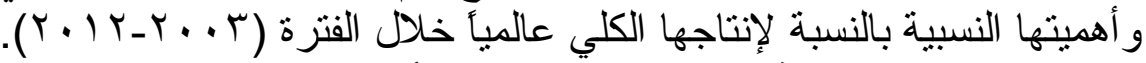

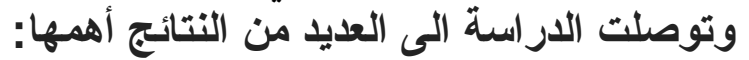

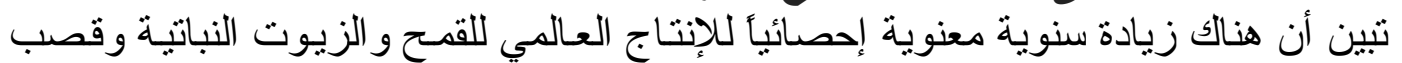

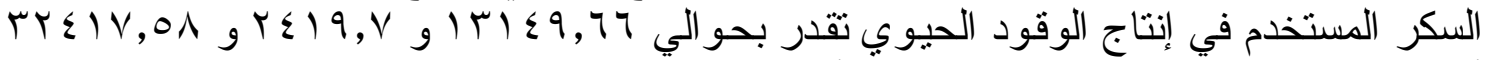

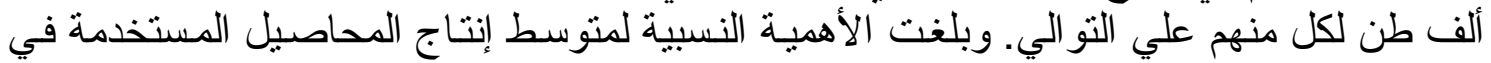

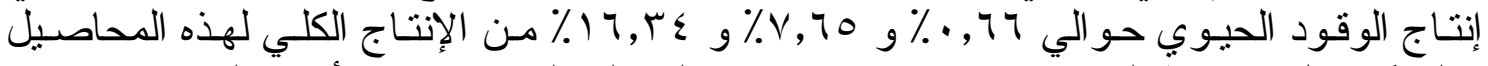

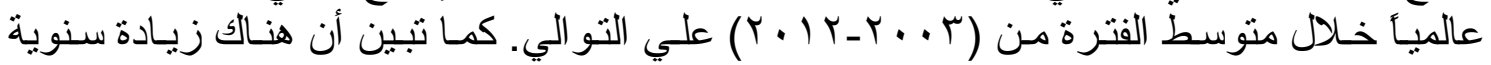

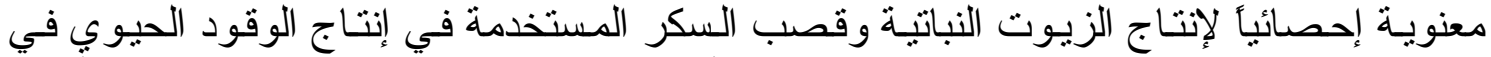

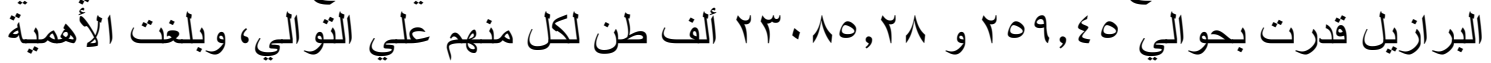

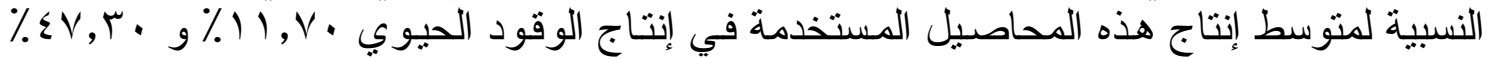

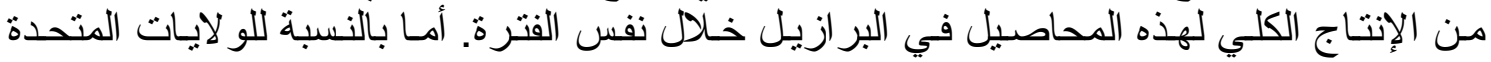
فكانت هنالك زيادة سنوية معنوية إحصائياً بالنسبة للحبوب الخشنة و الزئ الزيوت النباتية 


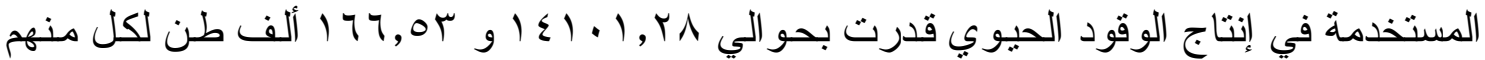

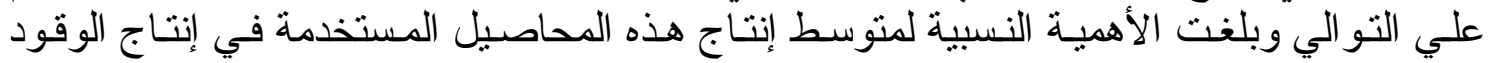

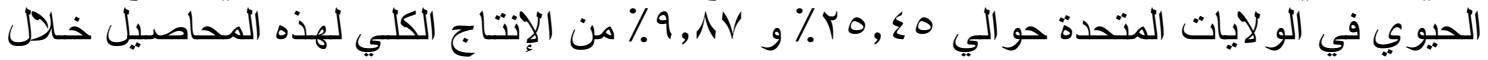

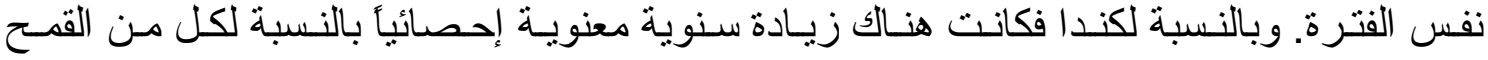

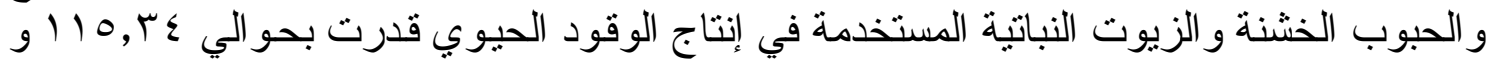

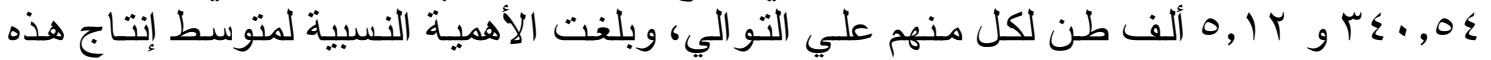

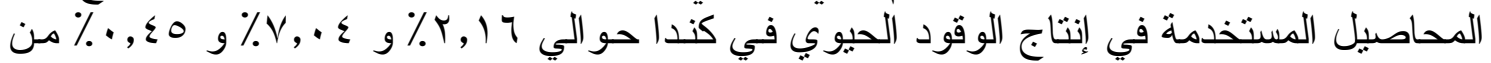

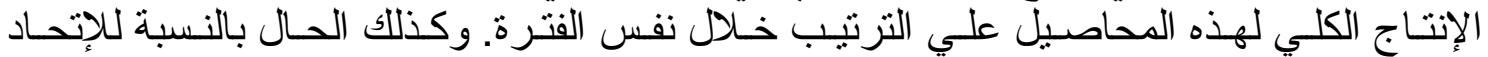

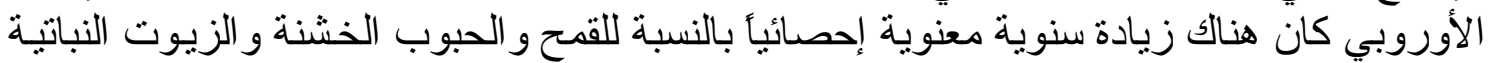

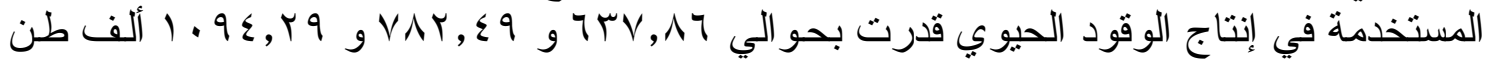

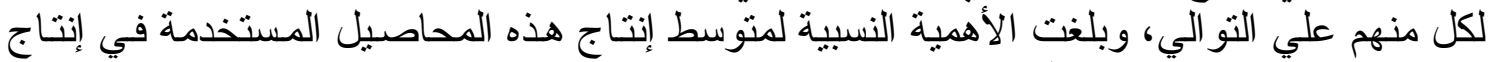

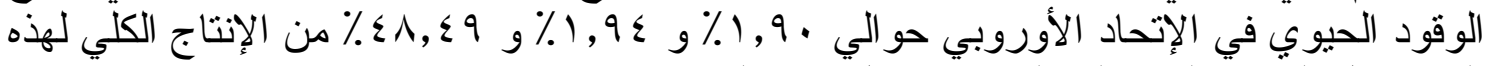
المحاصبل المشار إلبها علي الترديب الإدي خلاد نفس الفترة.

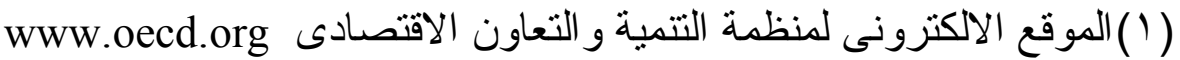

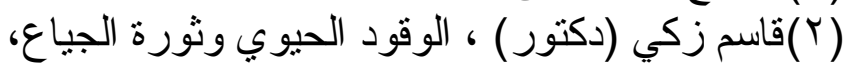

http://kenanaonline.com/users/KasemZakiAhmed/posts/83458

(3) http://www.Alwasatnews.com/4154/news/read/849554/1.htnl

$$
\text { ( ) اعات في: }
$$

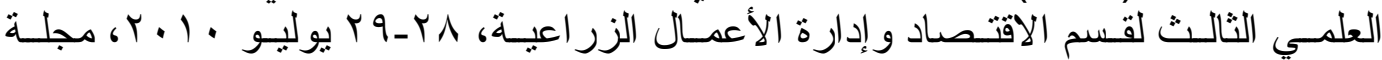

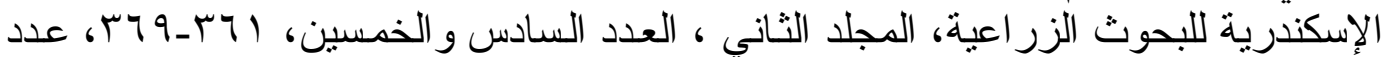

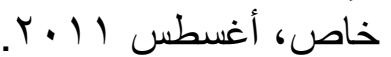

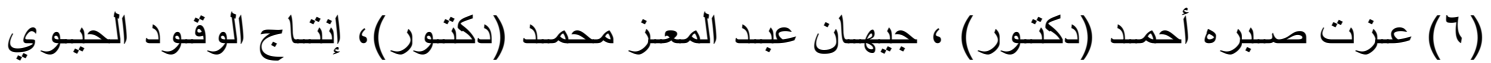

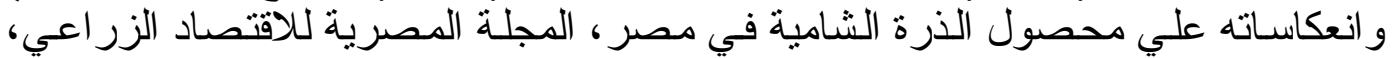

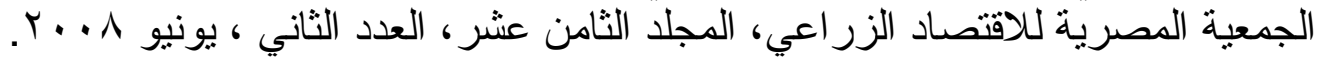

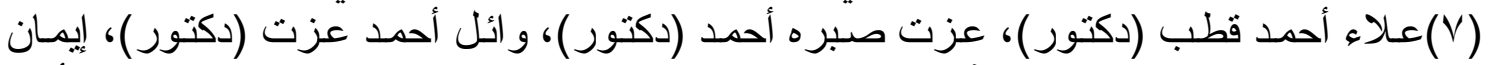

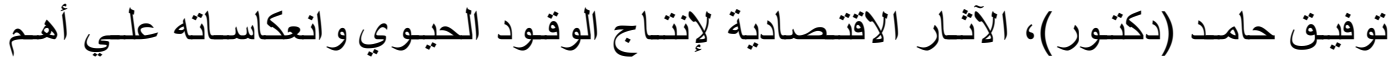

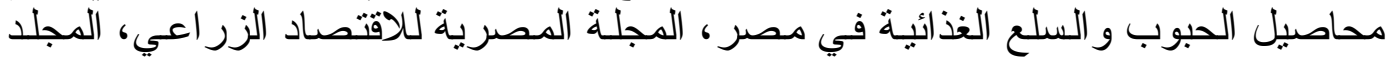

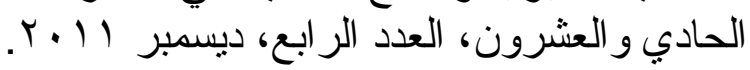

(8) Peter, J. and S. Thielmann (2008): Promoting biofuels: Implications for developing countries. Energy policy (36).

(9) Rask, K.J. and N. Rask (2011): Economic development and food productionconsumption balance: A growing global challenge. Food Policy, (36). 


\section{An Economic Study of the Most Important Food Crops used in Biofuel Production Globally \\ Wesam M.M.A. ${ }^{2}$; A. I. Mohamed ${ }^{1}$; Y.A. Hussein ${ }^{1}$ and Mona F.Georgy ${ }^{2}$ \\ ${ }^{1}$ Agric. Econ. Dept , Fac. of Agric. , Assiut Univ. , Assiut. \\ ${ }^{2}$ Agric. Res. Center}

\section{Abstract:}

Biofuel is extracted from plants as ethanol transparent colourless liquid characterized with special odour and speed great flare.

The present research problem represents in the global demand for agricultural food products where grains is the most important specially wheat, corn, sugar crops and vegetable oils used for extract ethanol and biodiesel. This global demand is the most important factor supporting the upward trend in prices; especially the two largest producers and exporters of these grains are the United States and Brazil.

The research aimed to study the development of production of the most important crops used in biofuels production and their relative importance for total global production during the period (2003-2012). The study concluded that:-

- There was an statistical annual significant increase of global production of wheat, vegetable oils and sugar cane used for biofuel production estimated about $13149.66,2419.7$ and 32417.58 thousand ton respectively. The relative importance of average crop production used for biofuel production about $0.66 \%, 7.65 \%$ and $16.34 \%$ of the total global production of these crops respectively within the mean period (2003-2012).

- In Brazil there was an statistical annual significant increase production of vegetable oils and sugar cane used for biofuel production estimated about 259.45 and 23085.28 thousand tons respectively and the relative importance of mean production of these crops used for biofuel production $11.70 \%$ and $47.30 \%$ of the total production of these crops within the same period.

- For USA, there was an statistical significant increase of coarse grains and vegetable oils used for biofuel production estimated about 14101.28 and 166.53 thousand ton respectively, while the relative importance for mean production of these crops used for biofuel production in USA about $25.45 \%$ and $9.87 \%$ of total production of these crops within the same period.

- For Canada, there was an statistical significant increase of wheat, coarse grains and vegetable oils used for biofuel production estimated about 115.34, 340.54 and 5.12 thousand ton respectively and the relative importance of mean production of these crops used for biofuel production estimated about $2.16 \%$, $7.04 \%$ and $0.45 \%$ of total production of these crops within the same period.

- For European Union, there was an statistical significant increase of wheat, coarse grains and vegetable oils used for biofuel production estimated about $637.86,782.49$ and 1094.29 thousand ton respectively and the relative importance of mean production of these crops used for biofuel production estimated about $1.90 \%, 1.94 \%$ and $48.49 \%$ of total production of these crops within the same period. 